\title{
Analytical Modelling of Built-up Steel Beams Using ANSYS
}

\author{
N. Shanmugasundaram and Prince G. Arulraj
}

\begin{abstract}
A Finite Element (FEM) model has been developed using Ansys 15 to analyse the built-up steel beams. The aim of this research work is to study the behavior of the built-up steel beams. When built-up sections have smaller depths, they may behave like a beam element and the bending moment may be predominant. When the depth becomes large, the built-up section may behave like a truss where in the bending moment will be negligible. At moderate depths, both bending moment and axial force may be predominant in the member. A parametric study has been performed for a number of beams with different geometry sections. Commercial finite element computer program ANSYS is used to perform linear as well as non-linear analysis for different models. The results of the ANSYS model were validated with result of the STAAD. Prosoftware. The forces, bending moment and deflections are computed and the behaviors of the built-up sections were analyzed. The details are presented in the paper.
\end{abstract}

Keywords--- Built-up Steel Beams, Truss, Beam, Behaviors

\section{INTRODUCTION}

$\mathrm{S}$ TEEL members exist in buildings and bridges in different forms. Understanding the behavior of these members under different loading is crucial for the development of an overall efficient and safe structure. Many methods have been used to study the behavior of steel members. The characteristics of the member are based on the geometry of the member. When the depth of built-up sections is small, then the member may behave like a beam. When the depth of member is large, then the member may behave like a truss. Experimental investigations have been widely used as a means to analyse the behavior of individual members under loading. While this method produces real life response, it is extremely time consuming, and the use of materials can be quite costly. Analytical investigations will save lot of time and money. Finite element analysis is one analytical method that can be used for a verity of engineering applications. Unfortunately, early attempts to accomplish this were also very time consuming due to the limitations of the software and hardware.

In recent years, however, the use of finite element analysis has increased due to progressing knowledge and capabilities of computer software and hardware. It has now become the preferred method to analyse complicated problems. The use of computer software to model these members is much faster and

N. Shanmugasundaram, $P G$ Scholar, SNS College of Technology, Coimbatore. E-mail:shancivilguy@gmail.com

Prince G. Arulraj, Dean, Department of Civil Engineering, SNS College of Technology, Coimbatore.E-mail:deancivil@snsct.org

DOI: 10.9756/BIJIEMS.7346 extremely cost-effective. More efficient and better analysis can be made to fully understand the behavior of the steel members and their contribution to a structure as a whole using FEM packages. An attempt has been made during the present study to model of built-up steel beams using finite element analysis.

\section{LITERATURE REVIEW}

Anwar Badawy Badawy Abu-Sena and Omer Nazmi Abdelnabi [1] investigated the buckling behavior of steel beam-column elements for the sake of developing an analytical model to calculate their ultimate resistance under axial compression and bending moment. The analytical model was based on Perry-type formulation and it accounted for the effect of initial imperfection. The model was validated by comparing its results with those obtained by the Finite Element Non-Linear Elasto-Plastic analysis using ANSYS 5.4 program. Finally, a simple but rational design method based on the model, was introduced. This method can be applied using a simple mathematical expression or charts and tables. The result of the developed design method was compared with the design method of the international codes of practice for design of steel structures. On light of these comparisons, a design recommendation was introduced.

Govindasamy.P, et al [2] carried out an investigation on cold form purlin sections under distortional buckling behaviour. The "C" purlins are now-a-days widely used in all industrial buildings. It is made up of steel sheets, thickness ranging from $0.8 \mathrm{~mm}$ to $5 \mathrm{~mm}$ and formed by cold process. It is extensively used for the advantage of lightweight, low cost and ease of manufacturing. They made an analysis to understand the behaviour of cold formed " $\mathrm{C}$ " purlins for gravity and wind load conditions. In actual practice compression flanges and tension flanges are laterally restrained by roof sheeting in gravity and wind loading respectively. For this study, Actual full scale model test was conducted in the laboratory, for above said boundary conditions. Uniformly distributed load was applied. Vertical and lateral deflections were measured. In addition, a numerical study using finite element analysis was done for the above said case. For the analysis, ANSYS 10.0 software was used. Finally a comparative study was made between theoretical and experimental results.

Rekha Bhoi and L.G.Kalurkar [3] presented the details of buckling behaviour of an I-beam under axial load on column and beam was examined. Buckling loads are critical loads where certain types of structure become unstable. The results of an extensive parametric study was presented in graphical form and summarized by simple design curves. The effect of critical buckling load for various symmetrical rolled 
I-sections like Indian Standard Junior Beam(ISJB), Indian Standard Light Weight Beam(ISLB), Indian Standard Medium Weight Beam(ISMB), Indian Standard Wide Flange Beam (ISWB), Indian Standard Heavy Weight Beam(ISHB) for different depths was calculated using the software Ansys. The results of critical buckling load calculated using Ansys were compared with the conventional method of Euler Buckling theory analytically.

A.Jayaraman, et al [4] carried out an investigation on the cold formed steel members. They compared the behavior and economy of cold formed steel (CFS) built up channel section and channel section of same cross sectional area. This study involved in the examination of theoretical and numerical investigations of specimens. Two specimens were designed and moments and shear forces at the critical cross-section with same configuration area were evaluated by keeping all other parameters constant. The theoretical data are calculated using Indian Standard code IS 801-1975 and the section properties of the specimens were obtained using IS 811-1975. The specimens were designed under uniformly distributed loading with simply supported condition. The theoretical results were verified using ANSYS V11 software. The research aimed to provide economical section with high bending strength, more load carrying capacity and high flexural strength. The studies revealed that the the channel sections have high bending strength, high load caring capacity, minimum deflection and distortional buckling when compared to the built up channel sections of same cross sectional area.

\section{PROPOSED METHOD OF ANALYSIS}

During the present study, five models were developed in ansys software. The first model had a span of $24 \mathrm{~m}$. The height of the model was varied from $0.15 \mathrm{~m}$ to $3 \mathrm{~m}$. The depths considered were $0.15,0.3,0.9,1.5$ and $3 \mathrm{~m}$. For each height/span ratio, the analysis was carried out in ANSYS. The first model is shown in figure 1 .

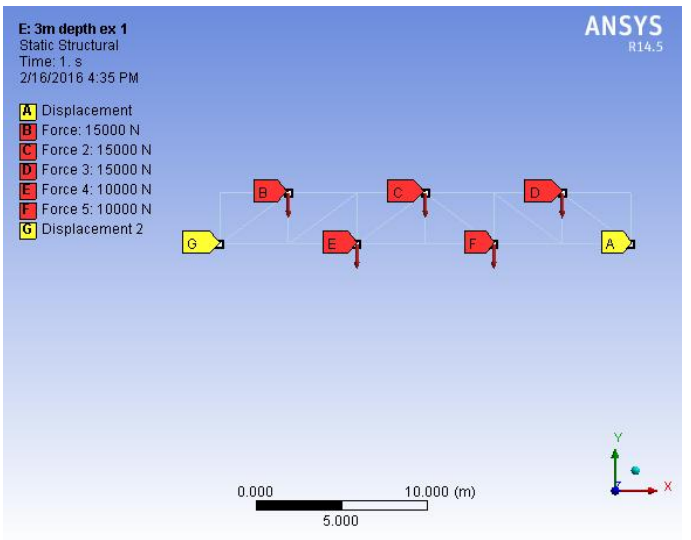

Figure 1: Modelling of 24m Span Beam

Figure 1 shows the geometry, support conditions and loading of the $24 \mathrm{~m}$ span beam. The dimension of member is $24 \mathrm{~m} \times 0.15 \mathrm{~m}$ for an angle section $100 \times 100 \times 20 \mathrm{~mm}$.

The span for the second model was $16 \mathrm{~m}$. In this case also five depths were considered. The depths carried were 0.15 , $0.3,0.19,1.5$ and $3 \mathrm{~m}$. For each height/span ratio, the analysis was carried out in ANSYS. The second model is shown in figure 2.

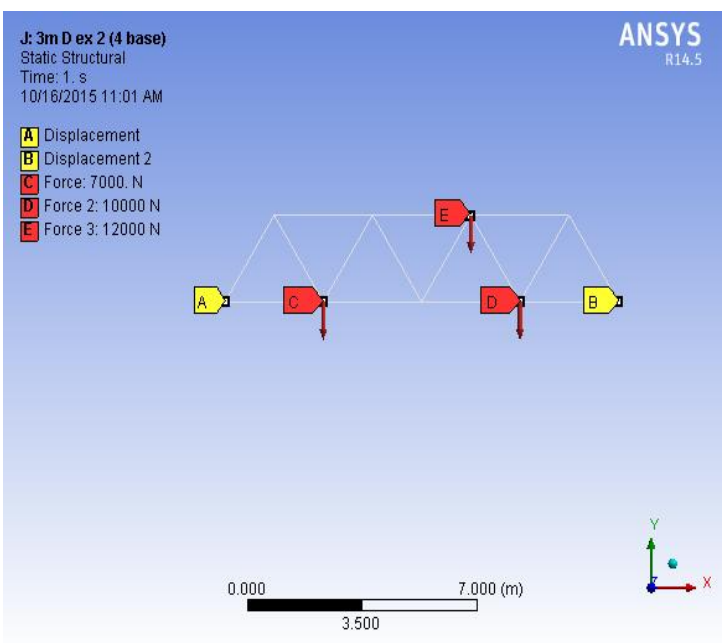

Figure 2: Modelling of 16m Span Beam

Figure 2 shows the geometry, support conditions and loading of the $16 \mathrm{~m}$ span beam. The dimension of member is $16 \mathrm{~m} \times 0.15 \mathrm{~m}$ for an angle section $100 \times 100 \times 20 \mathrm{~mm}$.

The third model considered had a span of $24 \mathrm{~m}$. The top and bottom chord members had a curved profile. In this case also five depths were considered. The depths carried were $0.15,0.3,0.19,1.5$ and $3 \mathrm{~m}$. For each height/span ratio, the analysis was carried out in ANSYS. The third model is shown in figure 3 .

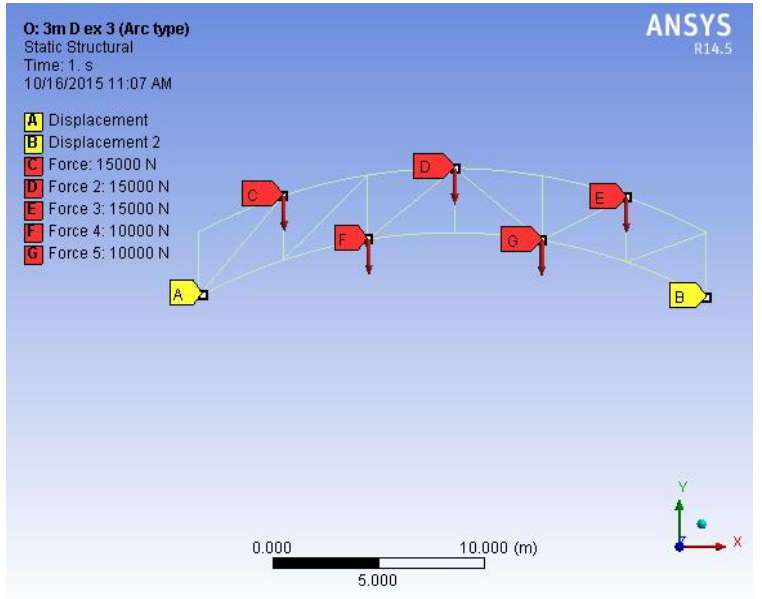

Figure 3: Modelling of 24m Span Curved Beam

Figure 3 shows the geometry, support conditions and loading of the $24 \mathrm{~m}$ span curved beam. The dimension of member is $24 \mathrm{~m} \times 0.15 \mathrm{~m}$ for an angle section $200 \times 200 \times$ $100 \mathrm{~mm}$.

The fourth and fifth model considered was a three and four angle built-up section. The span was $6 \mathrm{~m}$. The models was created using AUTO CAD then imported to ANSYS. In this both case also five depths were considered. The depths carried were $0.15,0.23,0.3,0.37$ and $0.45 \mathrm{~m}$. For each height/span ratio, the analysis was carried out in ANSYS. The fourth and fifth models are shown in figure 4 and 5 respectively. 


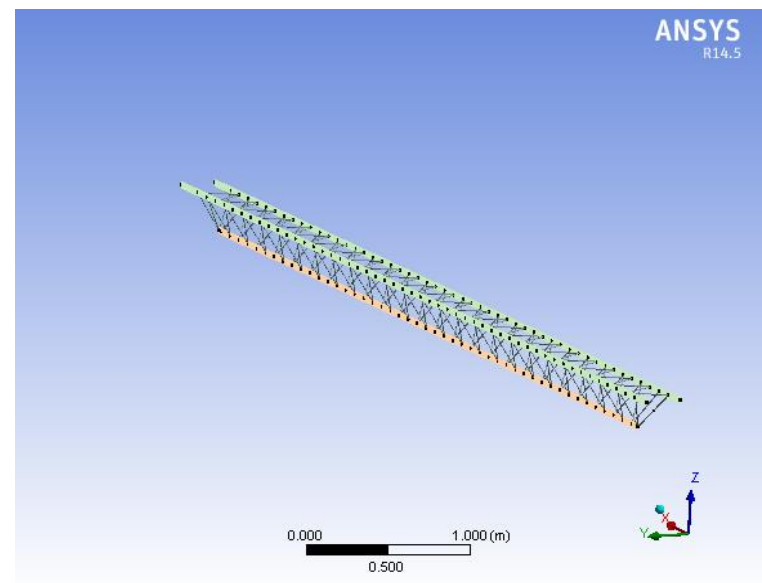

Figure 4: Geometry of the Three Angle Built-up Beam

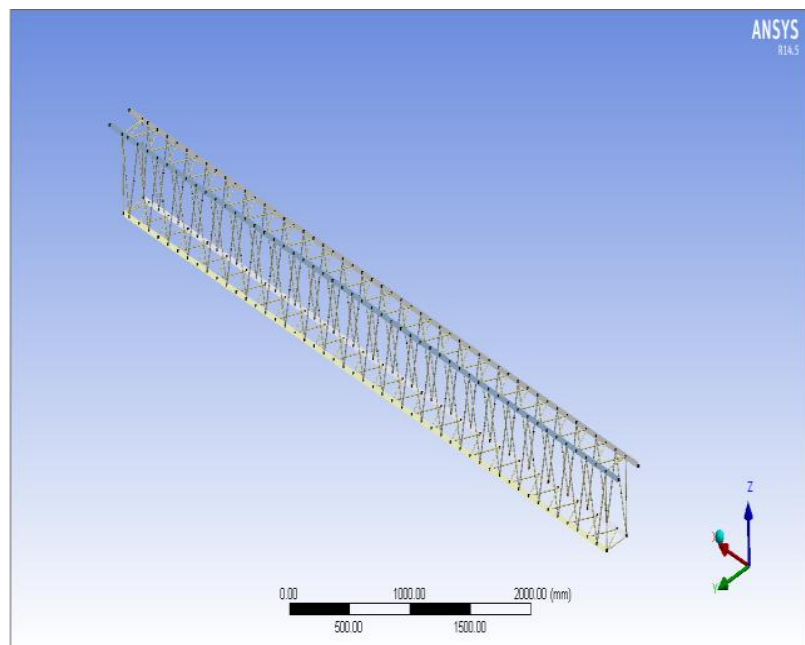

Figure 5: Geometry of the Four Angle Built-up Beam

Figure 4 and 5 shows the three and four angle built-up section consist of 3 and 4 number of IS angles 50x50x8mm connected using rods.

For each depth, the diameter of the connecting rods was changed to $8 \mathrm{~mm}, 10 \mathrm{~mm}, 12 \mathrm{~mm}, 16 \mathrm{~mm}, 20 \mathrm{~mm}$ and $25 \mathrm{~mm}$. The span of the member and the support conditions, load of the member and all other conditions remained the same. Altogether 60 models were created and analyzed.

All the models with different geometry were analyzed using the software ANSYS. The elements used for the analysis are given in table 1 .

Table 1: Elements Used

\begin{tabular}{|l|l|}
\hline Material type & Ansys element \\
\hline Steel reinforcement & Beam 188 \\
\hline Concrete & Solid 65 \\
\hline
\end{tabular}

The material properties of steel given as input for it ANSYS model are given in Table 2.

Table 2: Material Properties of Steel for the Proposed Model

\begin{tabular}{|c|l|l|l|}
\hline Material model no. & Element type & \multicolumn{2}{|l|}{ Material property } \\
\hline \multirow{2}{*}{2} & \multirow{3}{*}{ Beam 188} & \multicolumn{2}{|l|}{ Linear Isotropic } \\
\cline { 3 - 4 } & & Ex & $200 \mathrm{kN} / \mathrm{mm}^{2}$ \\
\cline { 3 - 4 } & & $\mathrm{PRXY}$ & 0.3 \\
\hline
\end{tabular}

\section{RESUlTS AND DisCUSSIONS}

\section{A. Results}

The comparison of the maximum bending moment, axial force and deflection for the five models were given below.

Table 3: Comparison of Bending Moments for the 24m Span Beam

\begin{tabular}{|l|l|l|l|}
\hline $\begin{array}{l}\text { D/L } \\
\text { (Ratio) })\end{array}$ & $\begin{array}{l}\text { Max.BM at T.C } \\
(N . m)\end{array}$ & $\begin{array}{l}\text { Max.BM at B.C } \\
(N . m)\end{array}$ & $\begin{array}{l}\text { Max.BM at I.M } \\
(N . m)\end{array}$ \\
\hline 0.00625 & 24233 & 18580 & 24233 \\
\hline 0.0125 & 10548 & 8248.1 & 10548 \\
\hline 0.0375 & 1213.3 & 957.14 & 1213.3 \\
\hline 0.0625 & 384.2 & 315.27 & 384.2 \\
\hline 0.125 & 89.661 & 86.883 & 89.661 \\
\hline
\end{tabular}

From the Table 3 gives the comparison of the maximum bending moment for the top chord, bottom chord and inclined member for different depth/length ratio of the $24 \mathrm{~m}$ span beam.

Table 4: Comparison of Axial Force for the 16m Span Beam

\begin{tabular}{|l|l|l|l|}
\hline D/L (Ratio) & $\begin{array}{l}\text { Max.AF at T.C } \\
(N)\end{array}$ & $\begin{array}{l}\text { Max.AF at B.C } \\
(N)\end{array}$ & $\begin{array}{l}\text { Max.AF at } \\
\text { I.M(N) }\end{array}$ \\
\hline 0.0125 & 98600 & 256350 & 106000 \\
\hline 0.025 & 58800 & 143090 & 59000 \\
\hline 0.075 & 23656 & 49374 & 23656 \\
\hline 0.125 & 17277 & 29704 & 17277 \\
\hline 0.25 & 14471 & 18826 & 14471 \\
\hline
\end{tabular}

From the Table 4 gives the value of the maximum axial force for the top chord, bottom chord and inclined member for different depth/length ratio of the $16 \mathrm{~m}$ span beam.

Table 5: Comparison of Bending Moments for the 24m Span Curved Beam

\begin{tabular}{|l|l|l|l|}
\hline $\begin{array}{l}\text { D/L } \\
\text { (Ratio) }\end{array}$ & $\begin{array}{l}\text { Max.BM at T.C } \\
(\text { N.m })\end{array}$ & $\begin{array}{l}\text { Max.BM at I.M } \\
(\text { N.m })\end{array}$ & $\begin{array}{l}\text { Max.BM at V.M } \\
(\text { N.m })\end{array}$ \\
\hline 0.00625 & 38357 & 38357 & 18836 \\
\hline 0.0125 & 26896 & 26896 & 19221 \\
\hline 0.0375 & 4511.7 & 5719.3 & 5719.3 \\
\hline 0.0625 & 1968 & 2016.6 & 2016.6 \\
\hline 0.125 & 1691.2 & 2091.6 & 2091.6 \\
\hline
\end{tabular}

From the Table 5 gives the comparison of the maximum bending moment for the top chord, inclined and vertical members for different Depth/Length ratio of the $24 \mathrm{~m}$ span curved beam.

Table 6: Comparison of Bending Moment, Axial Force and Deflection for the Three Angle built-up Beam (0.23m Depth)

\begin{tabular}{|l|l|l|l|}
\hline $\begin{array}{l}\text { Dia of } \\
\text { rod }(\mathrm{mm})\end{array}$ & BM(N.m) & $\begin{array}{l}\text { Axial } \\
\text { force }(\mathrm{N})\end{array}$ & Deflection $(\mathrm{m})$ \\
\hline 8 & 1820.7 & 73172 & 0.012091 \\
\hline 10 & 1755.4 & 73754 & 0.010982 \\
\hline 12 & 1716.2 & 74095 & 0.010364 \\
\hline 16 & 1668.5 & 74472 & 0.0097253 \\
\hline 20 & 1637 & 74671 & 0.0094251 \\
\hline 25 & 1617.5 & 74784 & 0.0091968 \\
\hline
\end{tabular}

From the Table 6 gives the comparison of bending moment, axial force and deflection for different diameter of rods of the three angle built-up beam. 
Table 7: Comparison of Bending Moment, Axial Force and Deflection for the Four Angle built-up Beam $(0.37 \mathrm{~m}$ depth)

\begin{tabular}{|l|l|l|l|}
\hline $\begin{array}{l}\text { Dia of } \\
\text { rod } \mathrm{mm})\end{array}$ & BM $(\mathrm{N.m})$ & $\begin{array}{l}\text { Axial } \\
\text { force }(\mathrm{N})\end{array}$ & Deflection $(\mathrm{m})$ \\
\hline 8 & 1206.8 & 24440 & 0.005665 \\
\hline 10 & 1110.4 & 24645 & 0.0044514 \\
\hline 12 & 1047 & 24767 & 0.0037738 \\
\hline 16 & 966.69 & 24922 & 0.0030806 \\
\hline 20 & 916.7 & 25022 & 0.0027487 \\
\hline 25 & 875.03 & 25096 & 0.0025293 \\
\hline
\end{tabular}

From the Table 7 gives the comparison of bending moment, axial force and deflection for different diameter of rods of the four angle built-up beam.

\section{B. Discussions}

The variation of the bending moment values for different depth/length ratio for the $24 \mathrm{~m}$ span beam is shown in figure 6 .

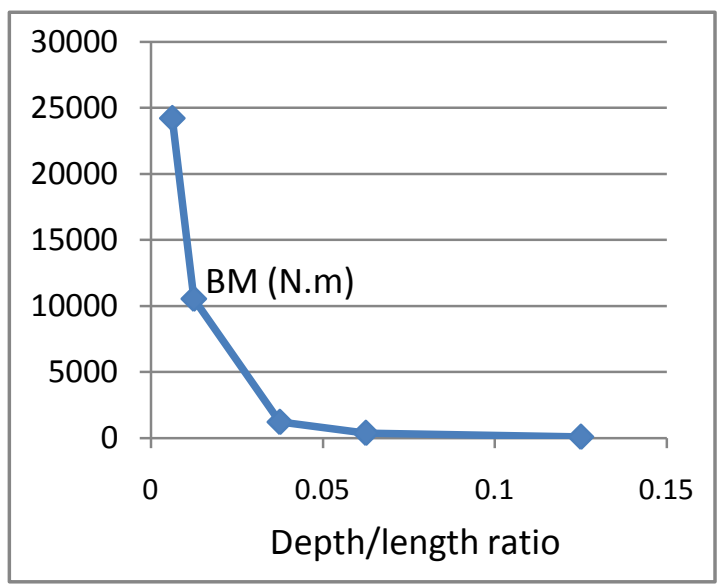

Figure 6: Effect of Depth/length Ratio on Total Bending Moment for the $24 \mathrm{~m}$ Span Beam

From the Figure 6, it can be seen that as the depth/length ratio increases, the bending moment values decrease and beyond 0.06 , the bending moment values were very small. Which indicate that truss action is predominant.

The variation of the axial force values for different depth/length ratio for the $16 \mathrm{~m}$ span beam is shown in figure 7 .

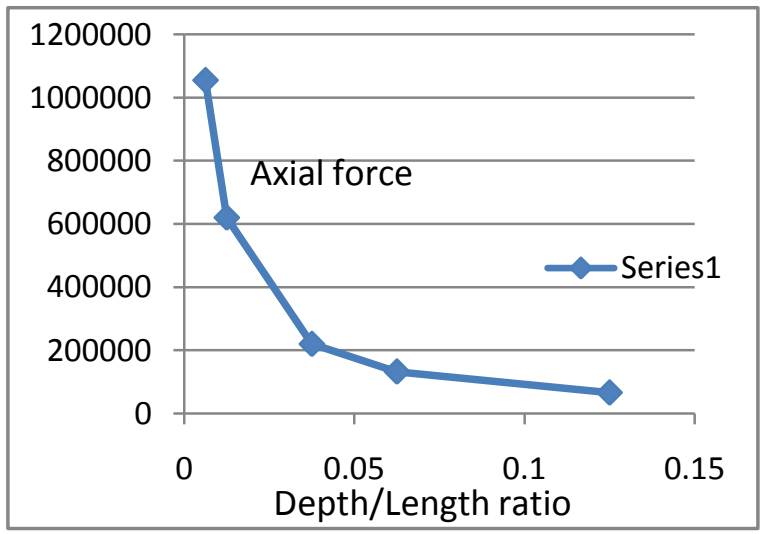

Figure 7: Effect of Depth/length Ratio on Total Axial Force for the $16 \mathrm{~m}$ Span Beam

From the Figure 7, it can be seen that as the depth/length ratio increases, the axial force values decrease and beyond 0.125 , the axial force values were very small.
The variation of the bending moment values for different depth/length ratio graph for $24 \mathrm{~m}$ span curved beam is shown in Figure 8.

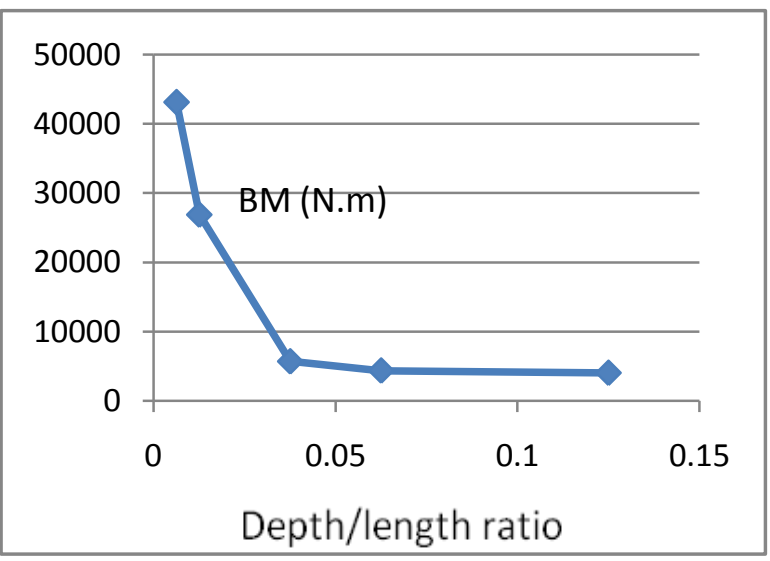

Figure 8: Effect of Depth/Length Ratio on Total Bending Moment for the $24 \mathrm{~m}$ Span Curved Beam

From the Figure 8, it can be seen that as the depth/length ratio increases, the bending moment values decrease and beyond 0.07 , the bending moment values were very small.

The variation of the bending moment values for different diameter of the connecting rods for the three angle built-up steel beam and depth of $0.23 \mathrm{~m}$ is shown in figure 9 .

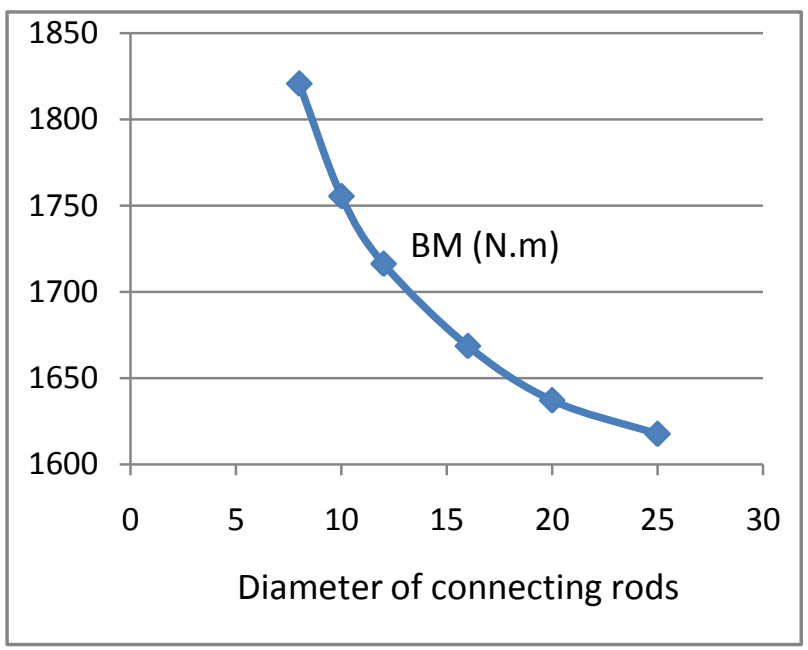

Figure 9: Effects of Diameter of Rods on Total Bending Moment for the Three Angle built-up Beam and Depth of $0.23 \mathrm{~m}$

From the Figure 9, it can be seen that as the diameter of the connecting members increases the bending moment decrease.

The variation of deflection values for different depth/length ratio for three angle built-up beam is shown in figure 10 . 


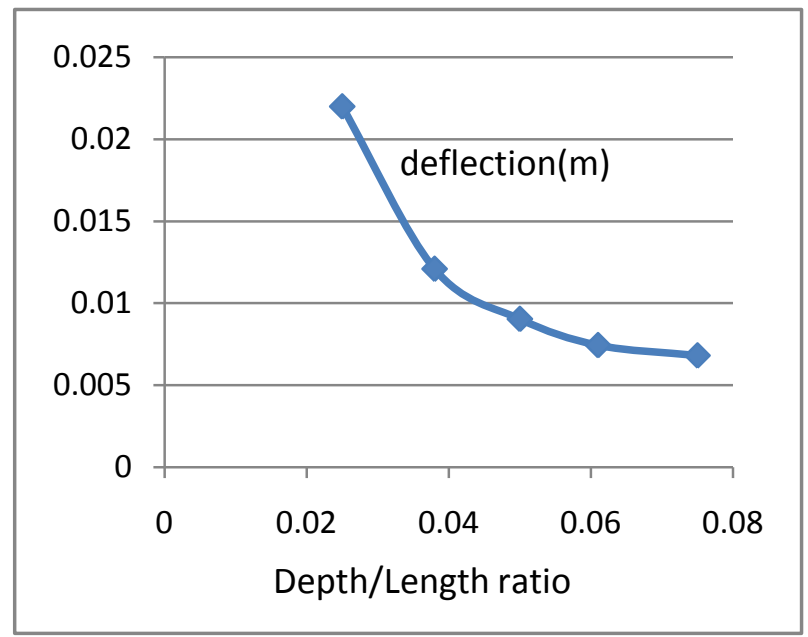

Figure 10: Effect of Depth/length Ratio on Maximum Deflection for the Three Angle Built-up Beam Using 8mm

Diameter of Rods

From the Figure 10, it can be seen that as the depth/length ratio increases, the deflection values decrease and beyond 0.07 , the deflection values were very small.

The variation of axial force values for different depth/length ratio for four angle built-up beam is shown in figure 11 .

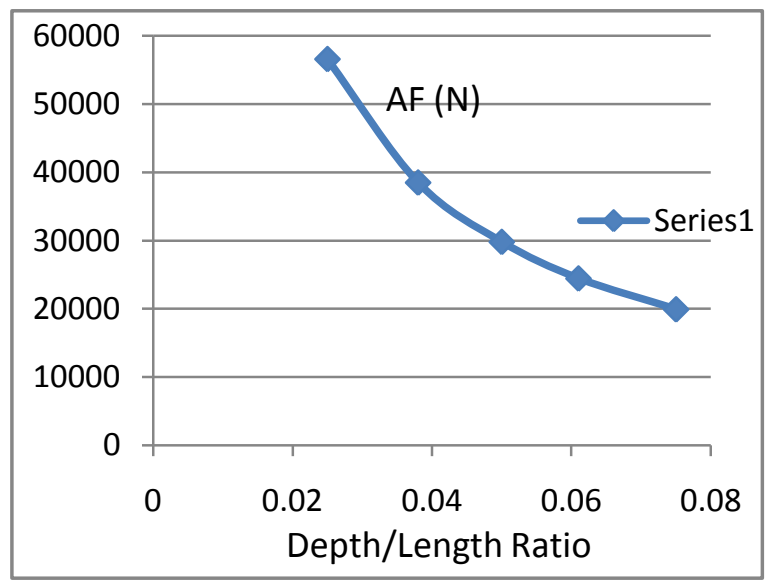

Figure 11: Effect of Depth/length Ratio on Maximum Axial Force for the Four Angle Built-up Beam Using 8mm Diameter of Rods

From the Figure 11, it can be seen that as the depth/length ratio increases, the axial force values decrease and beyond 0.06 , the axial force values were very small.

The variation of deflection values for different depth/length ratio for four angle built-up beam is shown in figure 12 .

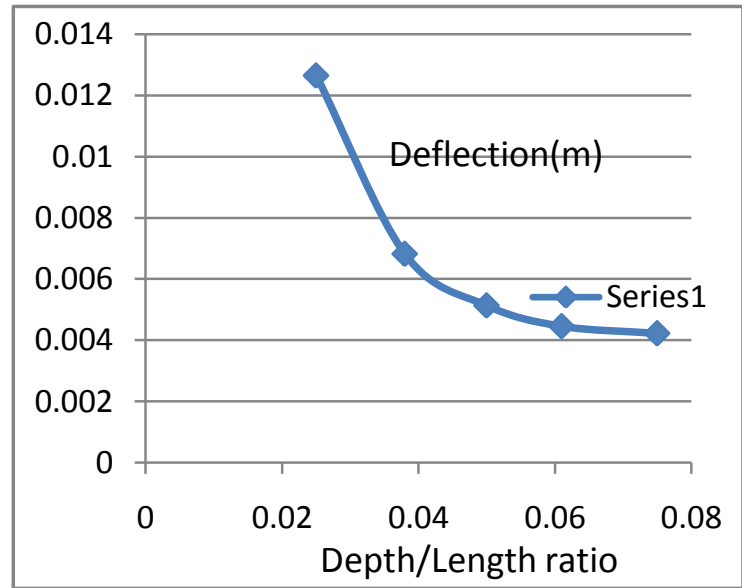

Figure 12: Effect of Depth/length Ratio on Maximum Deflection for the Four Angle Built-up Beam Using 10mm Diameter of Rods

From the Figure 12, it can be seen that as the depth/length ratio increases, the deflection values decrease and beyond 0.07 , the deflection values were very small.

The value of maximum and minimum bending moment for the three angle built-up beam is shown in figure 13 .

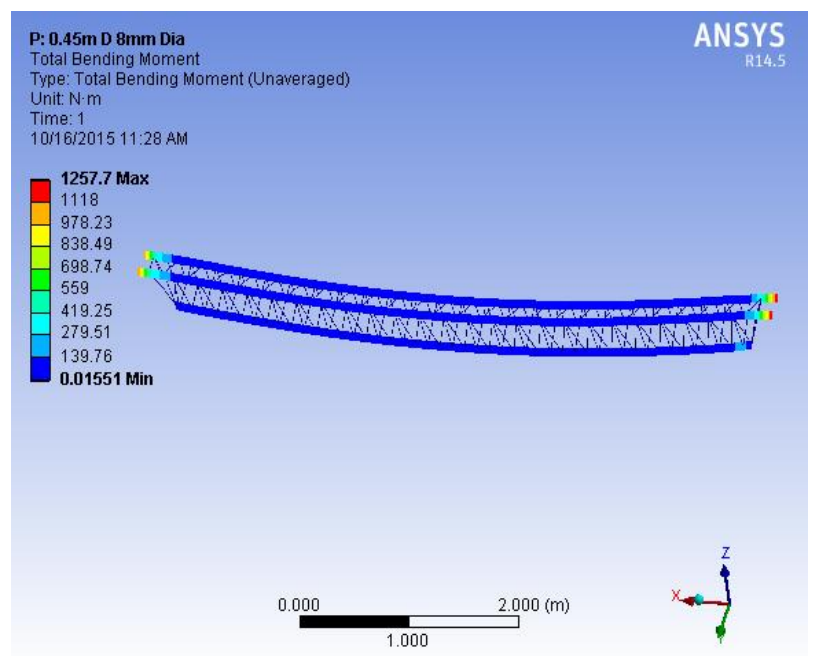

Figure 13: Maximum and Minimum Bending Moment for the Three Angle built-up Beam

From the Figure 13 shows the value of the maximum and minimum bending moments for the three angle built-up beam were found to be $0.01551 \mathrm{~N} . \mathrm{m}$ and $1257.7 \mathrm{~N} . \mathrm{m}$

The value of maximum and minimum axial force for the three angle built-up beam is shown in figure 14 . 


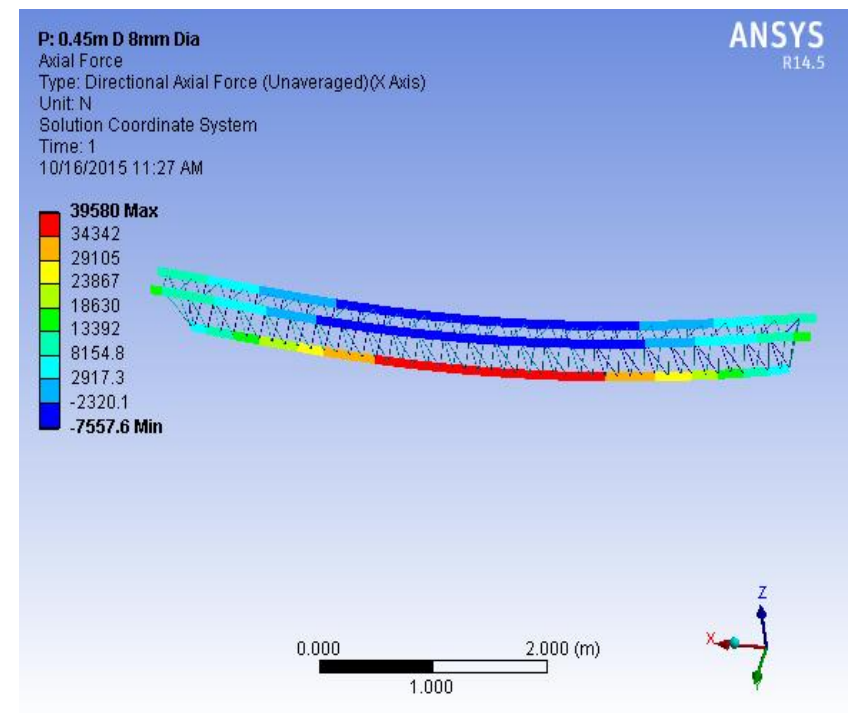

Figure 14: Maximum and Minimum Axial Force for the Three Angle Built-up Beam

From the Figure 14 shows the values of the maximum and minimum axial force for the three angle built-up beam were found to be $-7557.6 \mathrm{~N}$ and $39580 \mathrm{~N}$.

The value of maximum and minimum deflection for the four angle built-up beam is shown in figure 15 .

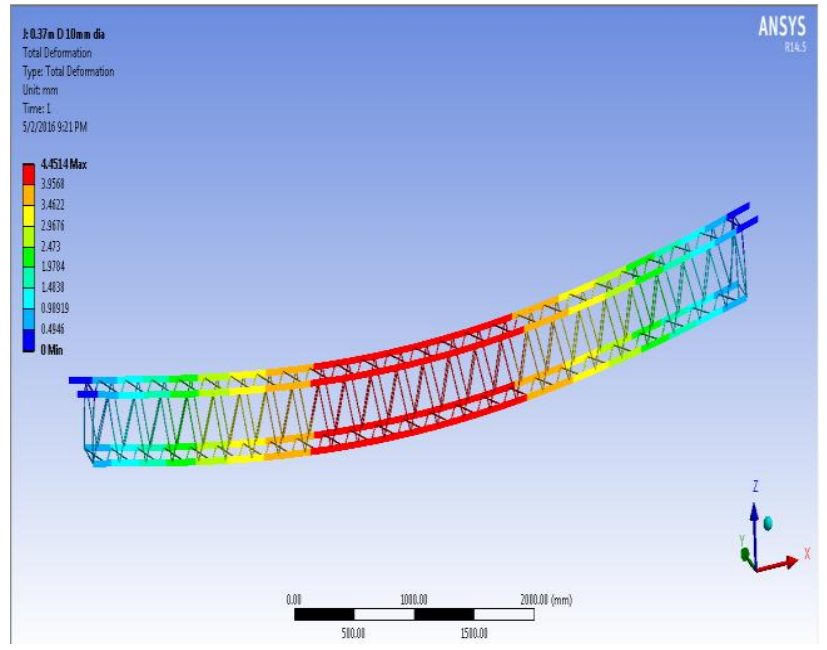

Figure 15: Maximum and Minimum Deflection for the Four Angle Built-up Beam

From the Figure 15 shows the values of the maximum and minimum deflection for the four angle built-up beam were found to be $0 \mathrm{~mm}$ and $4.4514 \mathrm{~mm}$.

\section{CONCLUSION}

An attempt has been made to understand the behavior of steel member using ANSYS. The main conclusions drawn from the current research are:

- It is found that as the depth/length ratio increases, the bending moment values decrease and the members behave like a truss.

- As the depth/length ratio increase the axial forces and deflection decrease.
- In case of built-up section, similar behavior was noticed.

- In case of built-up sections, as the size of the connecting members increase, the values of bending moment decrease.

\section{REFERENCES}

[1] A.B.B. Abu-Sena, M.S.A.D. Soliman and O.N.A.Abdel-Nabi, "Behavior and resistance of beam-column structural elements", Journal of Constructional Steel Research, 71, Pp.171-181, 2012.

[2] P. Govindasamy, V. Sreevidya, and L.S. Jayagopal, "Comparative Study on Cold Form Purlins for Distortional Buckling Behaviour", International journal of engineering sciences \& research technology, Vol. 2, No. 5, Pp. 1037-1043, 2013.

[3] L. Rekha Bhoi and G. Kalurkar, "Study of Buckling Behaviour of Beam and Column Subjected To Axial Loading for Various Rolled I Sections", International Journal of Innovative Research in Science, Engineering and Technology, Vol. 3, No.11, Pp. 17639-17645, 2014.

[4] A. Jayaraman, V. Senthilkumar and S. Athibaran, "Behavior and Design of Light gauge Cold Formed Steel Flexural Members (Comparison of Channel and Built up Channel Section)", International Journal of Scientific Engineering and Technology Research, Vol. 3, No.19, Pp. 3491-3946. 